Article

\title{
Assessing the Effects of Land Cover Land Use Change on Precipitation Dynamics in Guangdong-Hong Kong-Macao Greater Bay Area from 2001 to 2019
}

\author{
Xinghan Wang ${ }^{1,+}$, Peitong Cong ${ }^{2,+}$, Yuhao Jin ${ }^{2,+}$, Xichun Jia ${ }^{2}$, Junshu Wang ${ }^{3}$ and Yuxing Han ${ }^{3, *}$ \\ 1 Water Resources Remote Sensing Department, Pearl River Water Resources Research Institute, \\ Guangzhou 510610, China; xinghanwang@pearlwater.gov.cn \\ 2 College of Water Conservancy and Civil Engineering, South China Agricultural University, \\ Guangzhou 510642, China; slxyky@scau.edu.cn (P.C.); yuhao.jin@scau.edu.cn (Y.J.); \\ jiaxichun@stu.scau.edu.cn (X.J.) \\ 3 College of Electronic Engineering, South China Agricultural University, Guangzhou 510642, China; \\ junshuwang@stu.scau.edu.cn \\ * Correspondence: yuxinghan@scau.edu.cn \\ + These authors contributed equally to this work.
}

check for updates

Citation: Wang, X.; Cong, P.; Jin, Y.; Jia, X.; Wang, J.; Han, Y. Assessing the Effects of Land Cover Land Use Change on Precipitation Dynamics in Guangdong-Hong Kong-Macao Greater Bay Area from 2001 to 2019. Remote Sens. 2021, 13, 1135. https:// doi.org/10.3390/rs13061135

Academic Editors: Ranjeet John and Pradeep Wagle

Received: 24 January 2021

Accepted: 11 March 2021

Published: 17 March 2021

Publisher's Note: MDPI stays neutra with regard to jurisdictional claims in published maps and institutional affiliations.

Copyright: (c) 2021 by the authors. Licensee MDPI, Basel, Switzerland. This article is an open access article distributed under the terms and conditions of the Creative Commons Attribution (CC BY) license (https:/ / creativecommons.org/licenses/by/ $4.0 /)$.

\begin{abstract}
The change of spatial and temporal distribution of precipitation has an important impact on urban water security. The effect of land cover land use change (LCLUC) on the spatial and temporal distribution of precipitation needs to be further studied. In this study, transfer matrix, standard deviation ellipse and spatial autocorrelation analysis techniques were used. Based on the data of land cover land use and precipitation, this paper analyzed the land cover land use change and its influence on the spatial and temporal distribution pattern of precipitation in the GuangdongHong Kong-Macao Greater Bay Area (GBA). The results showed that from 2001 to 2019, the area of cropland, water, barren, forest/grassland in the GBA decreased by $44.03 \%, 8.05 \%, 50.22 \%, 0.43 \%$, respectively, and the area of construction land increased by $20.05 \%$. The precipitation in the GBA was mainly concentrated in spring and summer, and the precipitation in spring tended to increase gradually, while the precipitation in summer tended to decrease gradually, while the precipitation in autumn and winter has no obvious change. It was found that with the change of land cover land use, the spatial distribution of precipitation also changed. Especially in the areas where the change of construction land was concentrated, the spatial distribution of precipitation changed most obviously.
\end{abstract}

Keywords: precipitation dynamics; land cover land use change; urban water security; the GuangdongHong Kong-Macao Greater Bay Area

\section{Introduction}

The change of the spatial and temporal distribution of precipitation has an important impact on urban water security, and it is of great significance to discuss the change trend of precipitation center in the future to guarantee urban water security [1]. It has been showed that the temporal and spatial variation of precipitation was affected by many factors, among which land cover land use change (LCLUC) was an important influencing factor [2,3]. The impact of LCLUC on climate, especially precipitation, cannot be ignored. At present, many studies have been done on the impact of LCLUC [2,4], including temperature, circulation, carbon emissions, runoff-sediment [5], and other aspects [6-8]. However, there have also been studies on the negative environmental effects of anthropogenic LCLUC to improve crop production [9]. Some scholars have studied the effects of climate and LCLUC on water security in watersheds [1], while few studies specifically focus on the impact of LCLUC on precipitation.

LCLUC could affect the exchange of water, energy, greenhouse gases, non-greenhouse gases and aerosols between the land system and the atmosphere [10-12]. Albedo changes 
and greenhouse gas caused by these impacts will drive global climate change, while on a regional scale, the redistribution of energy and water vapor between land and atmosphere will contribute to regional climate change and affect precipitation distribution. At the same time, the ultrafine aerosol generated in the region will develop into cloud condensation nuclei, and can lead to the regional scale change of precipitation, so any change in aerosol source strength caused by man-made and climate change will generate feedback to the water budget [13]. Previous studies have suggested that the impact of LCLUC on the global average climate was not obvious, but that climate change on the regional scale was significant and varies with different types of land cover land use conversion [14,15]. Bounoua et al. indicated that judging from the average global temperature and precipitation caused by LCLUC, they can offset each other. Yan et al. found that worldwide, LCLUC via the biological effect of geophysics can offset the warming caused by greenhouse gases increase. At the same time, two studies that caused LCLUC on a regional scale climate change were significant $[14,16]$.

Most of the studies focused on the impact of urbanization on urban precipitation and the impact of forest or farmland on regional precipitation, while there were few studies on the underlying surface structure and the change of regional water resources in the water-air cycle [17-19]. It was found that the change of urban construction land has an important influence on the change of regional precipitation, vegetation, and land surface temperature, but it failed to quantitatively express the influence among them [20-22]. By analyzing long-term precipitation data, Zhang et al. found that the rapid expansion of urban land in Beijing since 1981 was statistically correlated with the decrease of summer precipitation in the northeast of Beijing from 1981 to 2005, and that the rise of surface temperature and the decrease of evaporation caused by urban expansion were the possible reasons for the change of summer rainfall [23]. In addition, the change in the spatial and temporal pattern of precipitation caused by the change of single land cover land use type has been observed and simulated by many scholars [24-26]. In terms of the change of forest types, some scholars found that deforestation and large-scale deforestation would lead to a significant decrease of average precipitation in all regions, and the conversion of tropical forests to barren would lead to a greater regional precipitation reduction than the conversion of grasslands. Large-scale afforestation in the pan-tropical and western European regions would increase precipitation $[27,28]$. In East Asia, Madi et al. used the CCSM (Community Climate System Model) to study and find that with the increasing of forest coverage in east Asian monsoon areas, the annual average precipitation increased, and the precipitation in April increased the most significantly, reaching 7\% [29]. Precipitation and the variations of land cover land use type considered the influence of each other, and most of the simulations showed that the farmland and pasture expanded at the expense of the trees and shrubs, and precipitation and surface temperature rise in the resulting Sahel region fell [30]. Studies have shown that when crops in the underlying surfaces of urban agglomerations in different regions in eastern China were changed to bare soil, evaporation reduced local water vapor significantly, which ultimately led to a decrease in precipitation [31]. In addition to the above studies, there were also studies on the change of land cover land use caused by a certain event and its influence on regional climate and precipitation. The construction of dams for agricultural irrigation affected the distribution of precipitation in the region [32]. The change of land cover land use did not exist in isolation but was accompanied by the mutual transformation of different land cover land use types. These transformation processes were often complex and difficult to distinguish separately, and their impacts on regional climate and precipitation were also different.

Therefore, the effect of LCLUC on the spatial and temporal distribution of precipitation needs to be further studied. In this study, transfer matrix, standard deviation ellipse and spatial autocorrelation analysis techniques were used to analyze the impact of land cover land use change, especially construction land and cropland change on regional precipitation. 


\section{Study Area}

The Guangdong-Hong Kong-Macao Greater Bay Area (GBA) is located between $111^{\circ} 21^{\prime} \mathrm{E}$ and $114^{\circ} 53^{\prime} \mathrm{E}$ and between $21^{\circ} 28^{\prime} \mathrm{N}$ and $24^{\circ} 29^{\prime} \mathrm{N}$ (Figure 1). It consists of Hongkong, Macao, and nine cities in Guangdong Province, covering a total area of 56,000 square kilometers. Affected by the subtropical humid climate, the GBA is warm and humid all year round, cloudy, and rainy, with an average annual precipitation of $1800 \mathrm{~mm}$ and an average annual temperature of $21.4-22.4^{\circ} \mathrm{C}$ [33]. Most of this region is lower than $200 \mathrm{~m}$ above sea level. Land cover land use types in the area include forest and grass land, water, cropland, construction land and other unused land. In the central Pearl River Delta alluvial plain, urbanization is highly concentrated and surrounded by cropland, with hills and mountains as the main three sides. Since 2000, the urbanization in the study area has developed rapidly, the land cover land use structure has undergone drastic changes, and the area of construction land has increased rapidly.

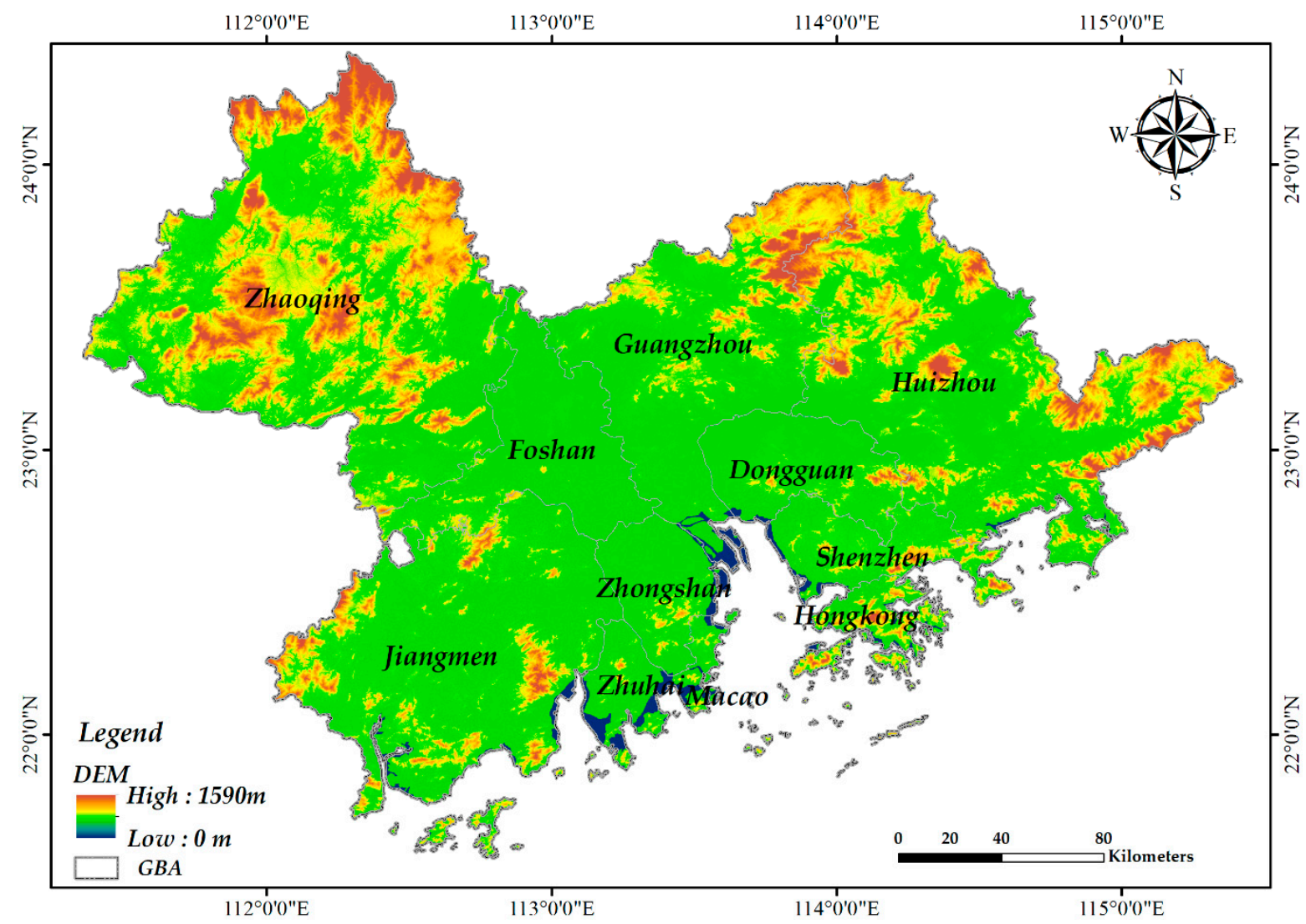

Figure 1. Map of study area. The elevation data are provided by International Scientific and Technical Data Mirror Site, Computer Network Information Center, Chinese Academy of Sciences.

\section{Data and Methods}

\subsection{Land Cover Land Use Data}

For the study of LCLUC, this study uses MODIS product data, which is the MCD12Q1v006 dataset. The MCD12Q1v006 dataset supplies global maps of land cover land use at annual time steps and $500 \mathrm{~m}$ spatial resolution from 2001-present. The data include the land cover land use maps set up by five different types of classification. Also included are a Quality Assurance (QA) layer, the posterior probabilities for the land cover land use classification system layers, and the binary land water mask used by the product. And in this study area, according to the results of the QA layer, the data quality is high.

In this paper, the global land cover land use classification scheme of the International Geosphere Biosphere Program (IGBP) is used. In the MCD12Q1v006 dataset, the annual 
IGBP classification contains a total of 17 land cover land use subcategories, which is a classification system based on global land cover land use. However, some taxonomic categories, such as permanent snow and ice cover, do not exist in the climatic conditions in the study area. In addition, this study focuses on revealing the influence rules of land cover land use change on precipitation on the background of rapid urbanization. Therefore, the original 17 land cover land use subcategories were reclassified, which mainly included forest and grass land, water, cropland, construction land and barren.

\subsection{Precipitation Data}

The Precipitation data used in this paper are the Integrated multi-satellite Retrievals for Global Precipitation Measurement (IMERG). It is also the successor of the Tropical Rainfall Measurement Mission (TRMM). The United States and Japan have jointly proposed a new global precipitation monitoring program. The IMERG Final Run data set is obtained by calibrating, merging, and interpolating all satellite microwave precipitation estimates. In this study, the inverse distance weight method is used to carry out spatial interpolation, and the accuracy of the result is $99 \%$. Its spatial resolution is $0.1^{\circ}$ by $0.1^{\circ}$.

\subsection{Methods}

\subsubsection{Land Cover Land Use Data and Precipitation Data Processing}

Based on the obtained land cover land use data and precipitation data, to complete the research objectives proposed in this paper, the land cover land use data and precipitation data are processed, respectively. The detailed processing process is shown in Figure 2.

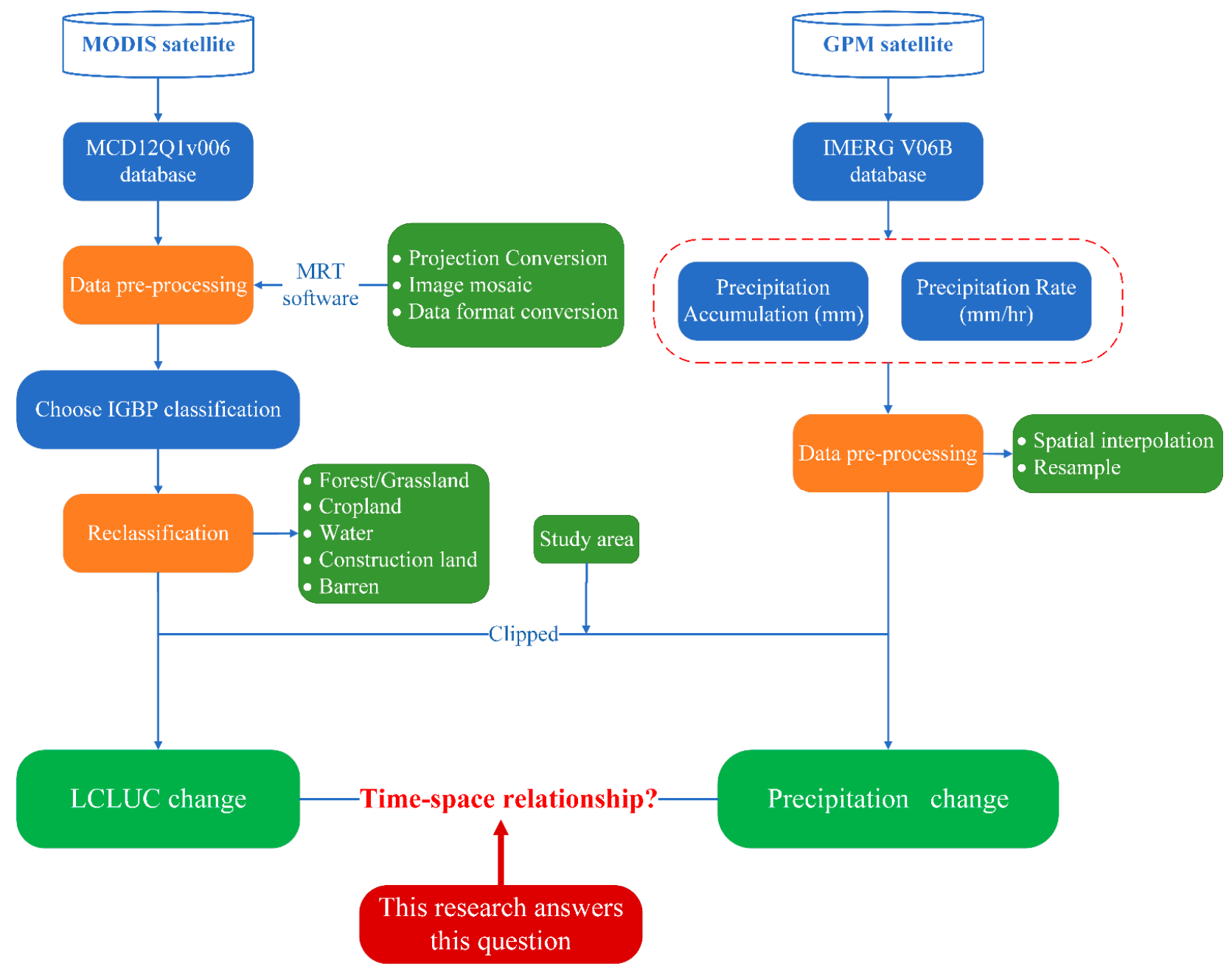

Figure 2. Methodological workflow. 
Firstly, the land cover land use data are preprocessed, which mainly includes projection conversion, image mosaic and data format conversion. Secondly, the existing land cover land use classification is combined with the needs of this study into forest/grassland, water, cropland, construction land and barren, as shown in Table 1. Then, the land cover land use data in the research area is clipped based on pretreatment, and raster data is converted into vector data. Finally, the transfer matrix was used to analyze the spatial transformation relationship of land cover land use types in different periods in 2001, 2004, 2008, 2011, 2016 and 2019.

Table 1. Land cover land use types and reclassification.

\begin{tabular}{cc}
\hline Land Cover Land Use Types & Reclassification \\
\hline $\begin{array}{c}\text { Evergreen Needleleaf Forests, Evergreen Broadleaf Forests, Deciduous } \\
\text { Needleleaf Forests, Deciduous Broadleaf Forests, Mixed Forests, Closed } \\
\text { Shrublands, Open Shrublands, Woody Savannas, Savannas, } \\
\text { Grasslands, Cropland/Natural Vegetation Mosaics }\end{array}$ & Forest/grassland \\
\hline Water Bodies, Permanent Wetlands & Water \\
\hline Croplands & Cropland \\
\hline Urban and Built-up Lands & Construction land \\
\hline Barren, Permanent Snow and Ice & Barren \\
\hline
\end{tabular}

3.3.2. Analysis Method of Temporal and Spatial Change of Land Cover Land Use and Precipitation

The land cover land use transfer matrix $[34,35]$ reflects the dynamic process information of the mutual transformation between different land cover land use types and areas in a certain period, and reflects the direction of land cover land use change guided by human activities. In this study, a total of 6 time periods of land cover land use transfer matrix statistical analysis, namely 2001-2004, 2004-2008, 2008-2011, 2011-2016, 2016-2019 and 2001-2019. The spatial autocorrelation method is used to analyze the spatial and temporal variation of precipitation.

\subsubsection{Elliptic Analysis of the Standard Deviation of Precipitation Data}

The standard deviation ellipse $[36,37]$ is useful to analyze the spatial and temporal variation of precipitation centers and the trend of spatial distribution of precipitation regions. The long axis and the short axis of the ellipse surface were output, as well as the direction of the ellipse. The direction represents the rotation angle of the long axis measured clockwise from the vertex. Many scholars have used this method to carry out research on spatial change [38-41].

In this study, spatial interpolation is first carried out according to the value of each pixel of precipitation satellite data, and then resampling is conducted based on the interpolation results. After resampling, the spatial resolution of precipitation data is $500 \mathrm{~m}$, which is consistent with the spatial resolution of land cover land use data.

\section{Results}

4.1. Spatial and Temporal Change Analysis of Land Cover Land Use from 2001 to 2019

\subsubsection{Analysis on the Characteristics of Land Cover Land Use Time Change}

From 2001 to 2019, land cover land use in the GBA has undergone great changes (Figure 3). The area of cropland has been decreased; the area of construction land has been increased significantly. The area of forest/grassland and water area fluctuated slightly around the average line. Among them, the cropland area showed a linear downward trend $\left(R^{2}\right.$ was 0.92$)$, and the construction land area showed a linear upward trend $\left(R^{2}\right.$ was 0.80$)$. Compared with 2001, in 2019, the area of cropland in the GBA decreased by $44.03 \%$, the area of water area decreased by $8.05 \%$, the area of barren decreased by $50.22 \%$, the area of forest/grassland decreased by $0.43 \%$ and the area of construction land increased by $20.05 \%$. 

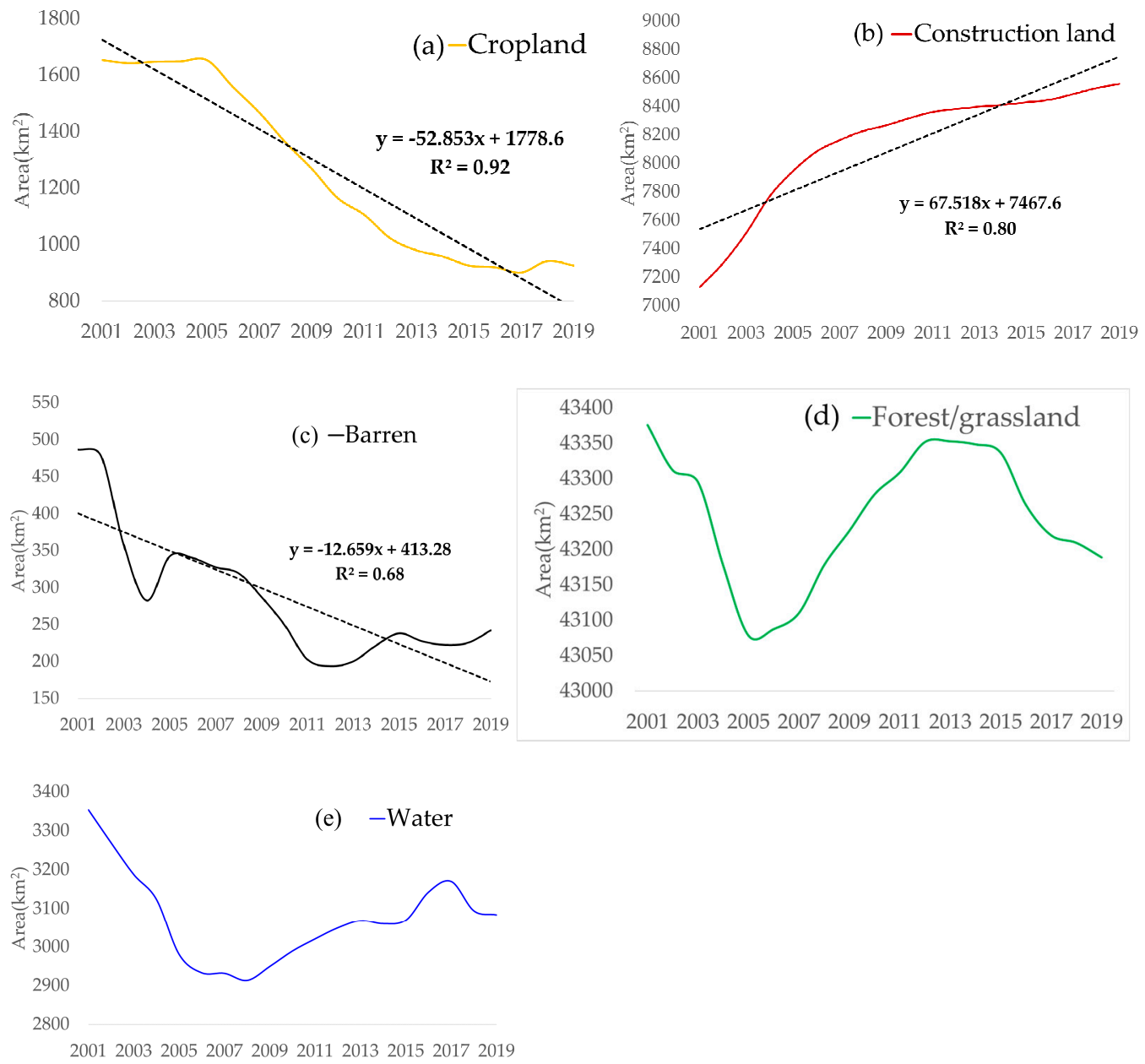

Figure 3. Land cover land use changed in the Greater Bay Area (GBA) from 2001 to 2019. (a) Cropland changed, (b) Construction land changed, (c) Barren changed, (d) Forest/grassland changed, (e) Water changed.

From the analysis of inter-annual changes (Table 2), the area of forest/grassland, water and barren decreased sharply, the area of construction land increased rapidly, and the area of cropland basically remained unchanged during 2001-2004. The change of land cover land use structure was mainly the transformation of forest/grassland, water, and barren into construction land, with the construction land area increasing by $635.73 \mathrm{~km}^{2}$, water area decreasing by $229.47 \mathrm{~km}^{2}$, forest/grassland area decreasing by $209.08 \mathrm{~km}^{2}$ and barren area decreasing by $203.06 \mathrm{~km}^{2}$. From 2004 to 2008 , the area of water and cropland continued to decrease while the area of construction land continued to increase. The construction land area increased by $451.66 \mathrm{~km}^{2}$, the water area decreased by $218.95 \mathrm{~km}^{2}$, and the cropland area decreased by $273.28 \mathrm{~km}^{2}$. From 2008 to 2011, the area of barren and cropland decreased by $104.60 \mathrm{~km}^{2}$ and $248.67 \mathrm{~km}^{2}$, respectively, while the area of construction land, water and forest/grassland increased by $132.05,96.03$ and $125.19 \mathrm{~km}^{2}$, respectively. From 2011 to 2016, the cropland area continued to decrease at a high rate. In this stage, the cropland area decreased by $199.37 \mathrm{~km}^{2}$, and the water area continued the growth trend of the previous stage, with the area increasing by $106.69 \mathrm{~km}^{2}$, and the construction land area's increased speed further slowed down. From 2016 to 2019, land cover land use changes were mainly concentrated in construction land, with an increase of $108.95 \mathrm{~km}^{2}$. 
Table 2. Land cover land use changed for different types in the GBA $\left(\mathrm{km}^{2}\right)$.

\begin{tabular}{cccccccc}
\hline & & $\mathbf{2 0 0 1 - 2 0 0 4}$ & $\mathbf{2 0 0 4 - 2 0 0 8}$ & $\mathbf{2 0 0 8 - 2 0 1 1}$ & $\mathbf{2 0 1 1 - 2 0 1 6}$ & $\mathbf{2 0 1 6 - 2 0 1 9}$ & $\mathbf{2 0 0 1 - 2 0 1 9}$ \\
\hline & Cropland & -5.88 & 273.28 & 248.67 & 199.37 & -4.81 & 710.63 \\
Land cover & Barren & 203.06 & -42.05 & 104.60 & -26.63 & -11.96 & 227.02 \\
land use & Construction land & -635.73 & -451.66 & -132.05 & -87.00 & -108.95 & -1415.39 \\
& Water & 229.47 & 218.95 & -96.03 & -106.69 & 63.10 & 308.80 \\
& Forest/grassland & 209.08 & 1.48 & -125.19 & 20.95 & 62.62 & 168.94 \\
\hline
\end{tabular}

Note- greater than 0 means an increase in area, and less than 0 means a decrease in area.

\subsubsection{Analysis of Spatial Variation Characteristics of Land Cover Land Use}

The land cover land use types of GBA were mainly forest/grassland, accounting for about $70 \%$ of the total land area, mainly distributed in Zhaoqing city, Jiangmen City and Huizhou city. Construction land was mainly concentrated in the Plain area of the Pearl River Delta (Figure 4). In 2001, cropland was mainly distributed in Zhaoqing city, Jiangmen City and Huizhou city, while construction land was mainly distributed in Guangzhou city, Dongguan City, Shenzhen City and Foshan City (Figure 4a). During 2001-2008, with the development of the social economy, the construction land area increased rapidly (Figure 5a,b). At the same time, the area of cropland continued to decreased, which was mainly concentrated in Zhaoqing City, Huaiji County, Jiangmen Enping City, Kaiping City, Taishan City, Boluo County, Huizhou City and Huicheng City. From 2008 to 2019, the area of construction land continued to increase, but the space changed, radiating from the concentrated and contiguous Pearl River Delta to the surrounding cities (Figure 5c-e).
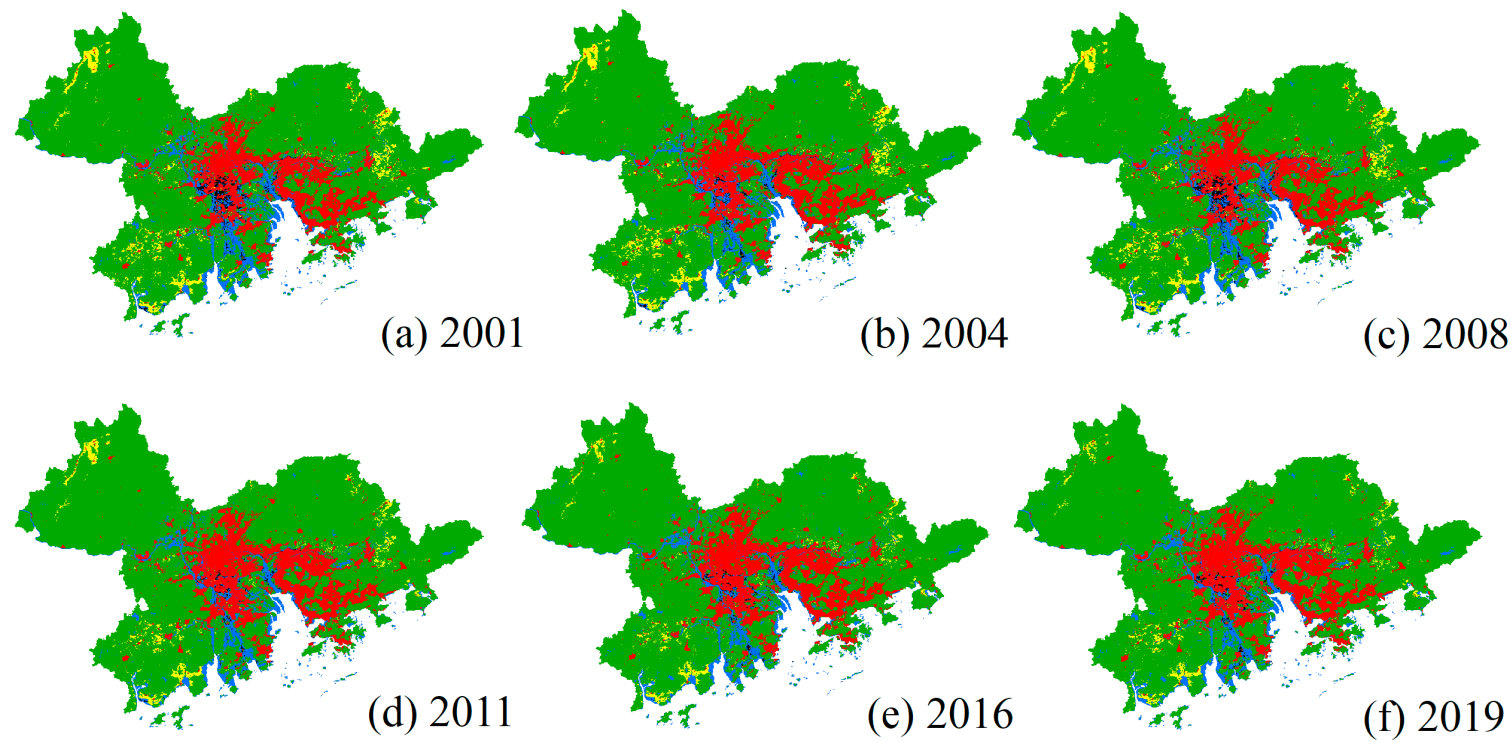

\section{Land cover land use types}
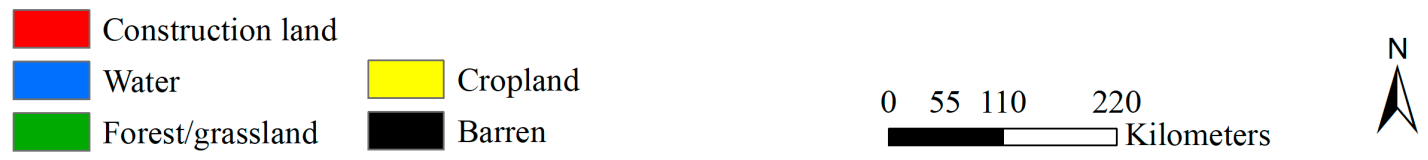

Figure 4. The spatial distribution of land cover land use in the GBA in 2001, 2004, 2008, 2011, 2016 and 2019. 

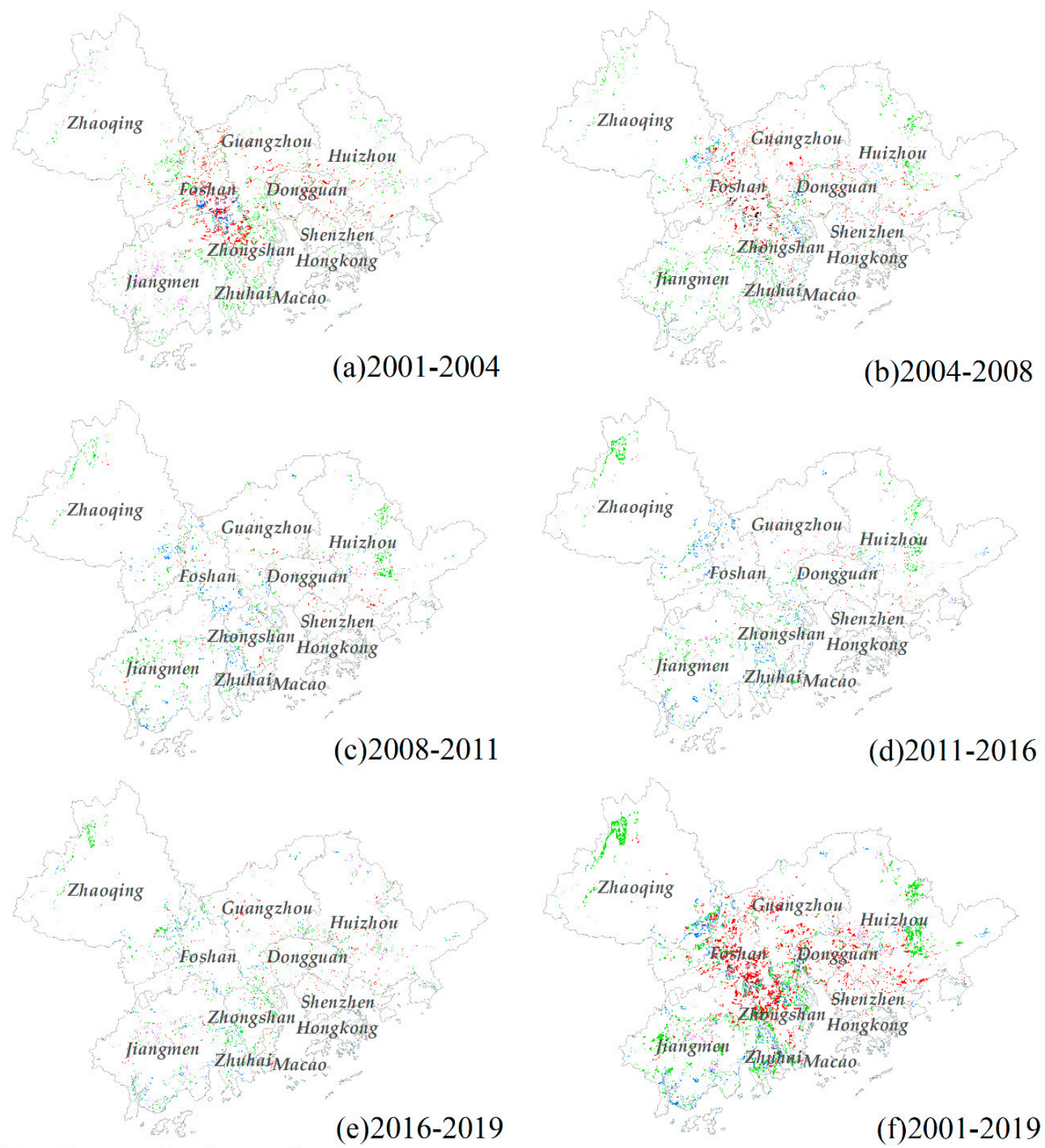

Land cover land use change

(e) 2016-2019

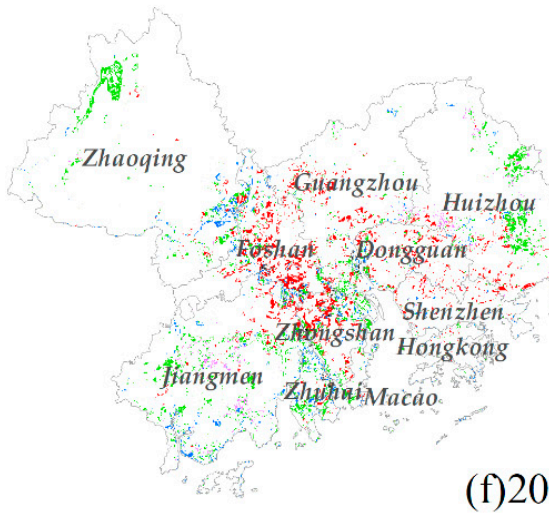

(f)2001-2019

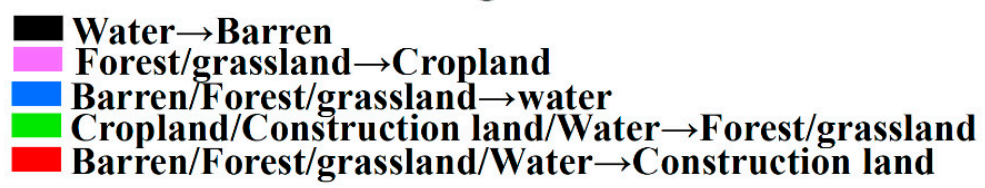

Figure 5. The spatial distribution of land cover land use changed in the GBA from 2001 to 2019.

\subsection{Spatial and Temporal Change Analysis of Precipitation from 2001 to 2019}

According to the monthly scale precipitation data of IMERG Final Run V06B data set, the annual cumulative total precipitation was obtained by adding the monthly scale data of each year. The annual cumulative precipitation in the research area was clipped. Then, based on the measured precipitation data and satellite precipitation data from 26 observation stations in the GBA, the correlation was established to conduct spatial calibration of satellite precipitation data. The analysis results (Figure 6) showed that the absolute value of the annual scale data of the IMERG Final Run V06B data set in the GBA was about two times smaller overall, but the linear correlation between the measured value and the satellite rainfall data was high, and the value of $\mathrm{R}^{2}$ was 0.94 . 


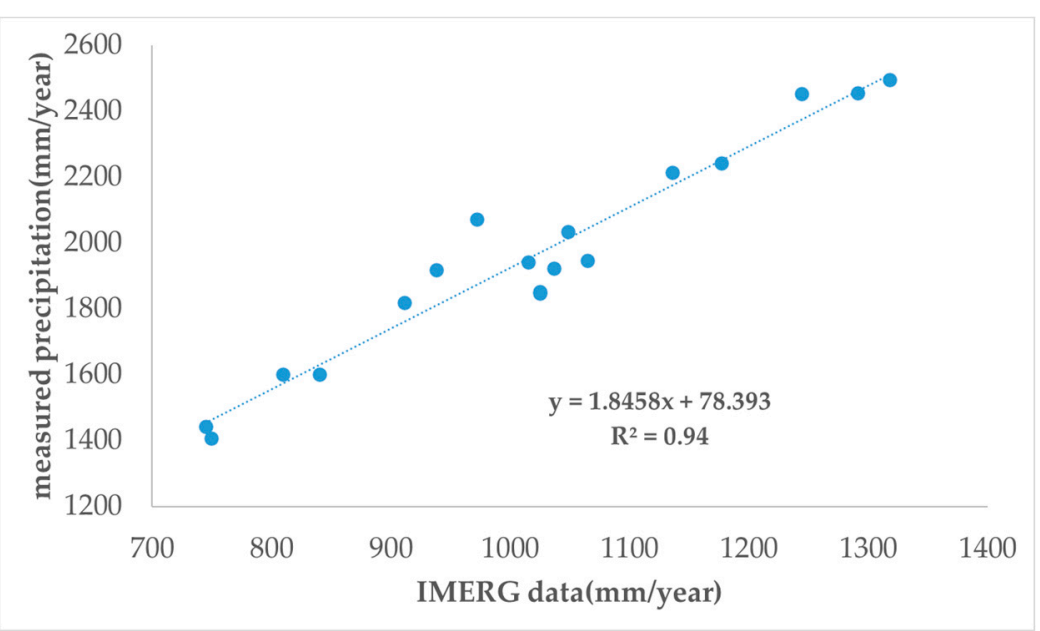

Figure 6. Correlation between observation station measurements and satellite rainfall data.

\subsubsection{Analysis of Annual Precipitation Change}

From 2001 to 2019, the annual precipitation in the GBA fluctuated around the mean line (Figure 7). Among them, there was a great variation among years, with a difference of more than $1000 \mathrm{~mm} /$ year between the year with extremely little rain and the year with an extreme amount of rain. The year with extremely little rain mainly included 2004 and 2011, with precipitation around $1400 \mathrm{~mm}$. The year with an extreme amount of rain mainly included 2001, 2008 and 2016, with annual precipitation around $2400 \mathrm{~mm}$. Among them, from 2001 to 2004, the annual precipitation decreased sharply, by about 50\%. From 2004 to 2008 , the annual precipitation showed a fluctuating upward trend, increasing by about $50 \%$. From 2008 to 2011, annual precipitation showed a fluctuating downward trend, decreasing by about $50 \%$. From 2011 to 2016, the annual precipitation showed a fluctuating rising trend, increasing by about 50\%. It showed an upward trend from 2016 to 2019.

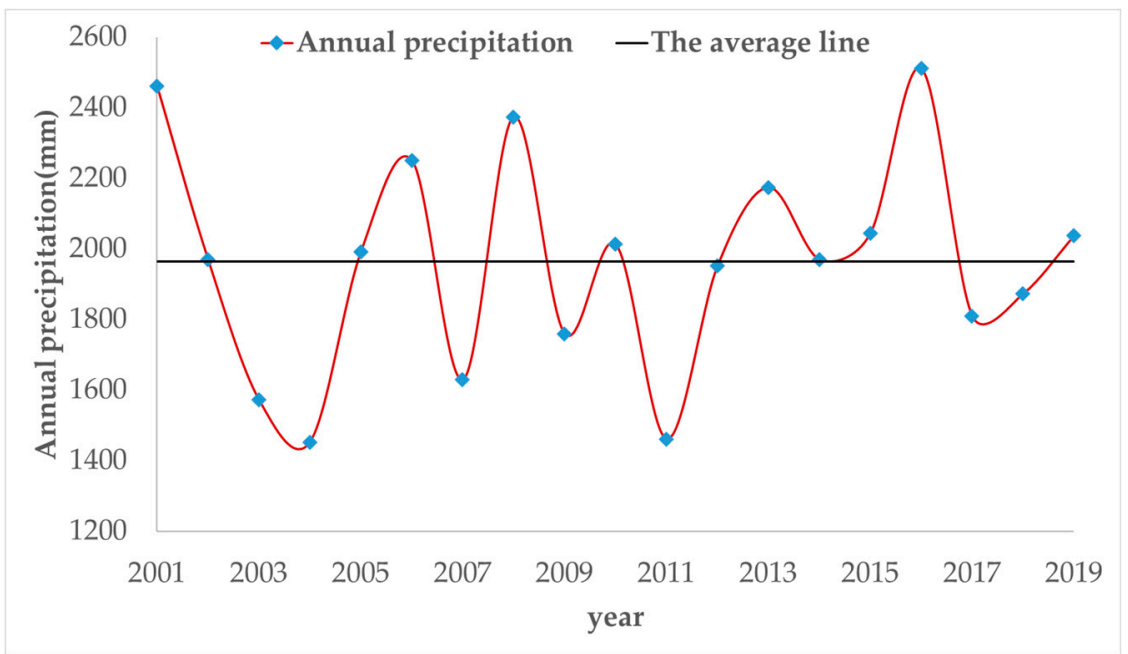

Figure 7. Total annual precipitation from 2001 to 2019.

During the period from 2001 to 2019, the spatial distribution of precipitation in the GBA also changed greatly and showed certain regularities. In the years with sufficient precipitation, the spatial distribution of precipitation was wide and mainly concentrated in the coastal areas within the GBA, such as 2001 (Figure 8a), 2008 (Figure 8c) and 2016 (Figure 8e). In the years with relatively low precipitation (Figure $8 b$ ), the spatial distribution range of precipitation was small, mainly concentrated in the central part of the study area, which was the region with the highest degree of urbanization. 
(a) 2001

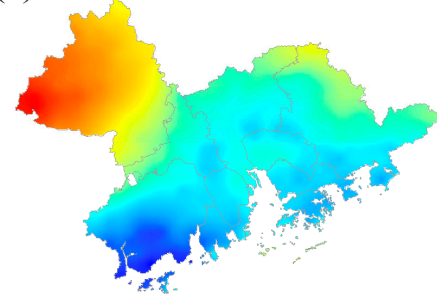

(d) 2011

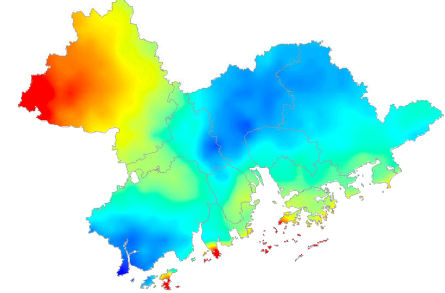

Legend

precipitation (b) 2004

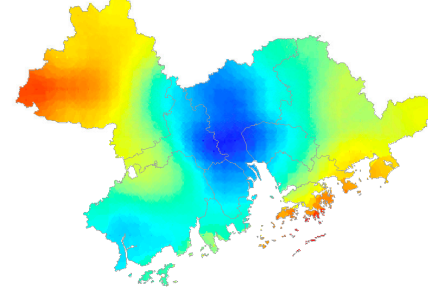

(c) 2008

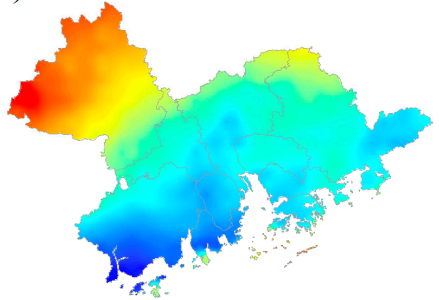

(f) 2019

(e) 2016
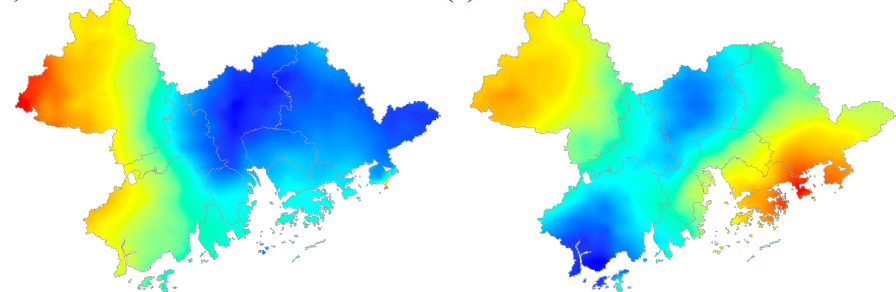

$0 \quad 100 \quad 200 \quad 400$

$\aleph^{N}$

Figure 8. Spatial distribution of precipitation in the GBA, 2001-2019.

At the same time, the central position of precipitation has also changed. During the period of 2001-2019, the precipitation centers in the GBA were mainly concentrated in the Nanhai District of Foshan (2004, 2005, 2008, 2011, 2012, 2016), Shunde District (2002, 2010, 2018), Haizhu District of Guangzhou (2006, 2015) and Panyu District of Guangzhou (2001, 2003, 2007, 2013, 2014, 2017, 2019), as shown in Figure 9.

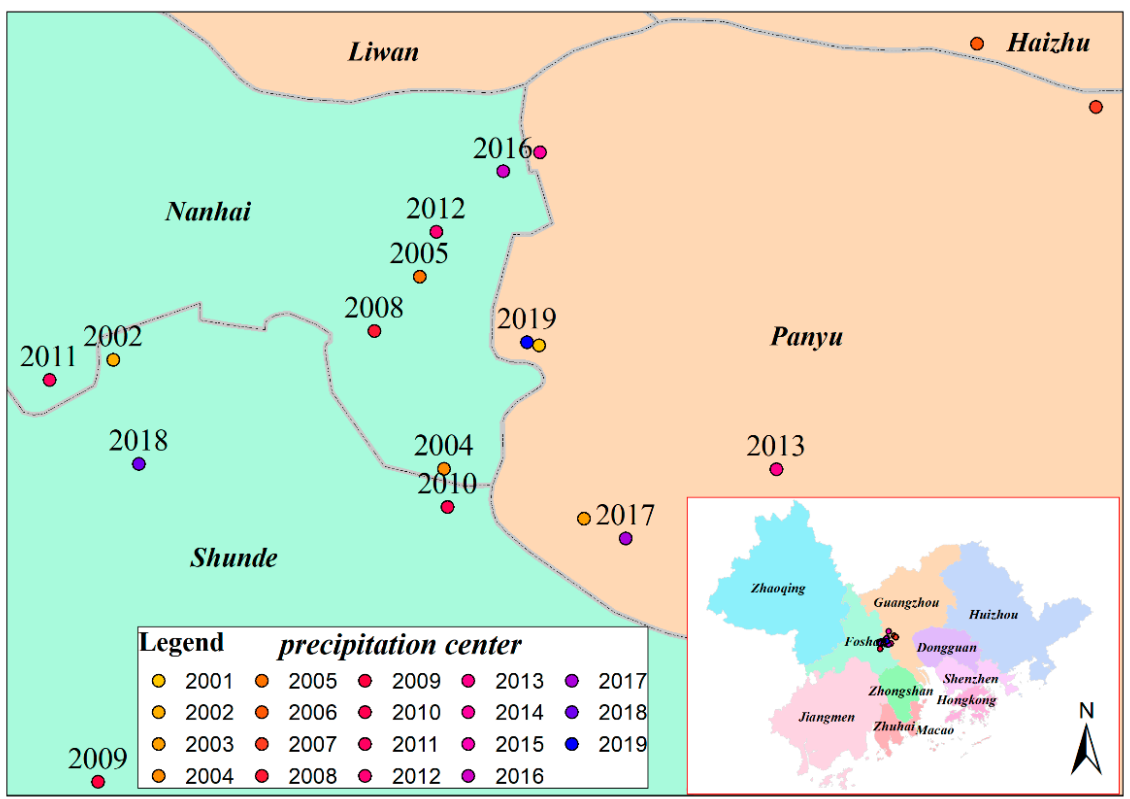

Figure 9. Spatial distribution of precipitation centers in the GBA from 2001 to 2019.

The elliptic analysis of standard deviation (Figure 10) showed that the spatial distribution of precipitation was mainly south to the east (from Zhaoqing to Foshan to Guangzhou to Dongguan) and north to the east (from Jiangmen to Foshan to Guangzhou). The spatial 
distribution of precipitation in 2003, 2009, 2010, 2013 and 2019 was east-by-north, and that in 2001, 2002, 2004, 2005, 2006, 2007, 2008, 2011, 2012, 2014, 2015, 2016, 2017 and 2018 was east-by-south.

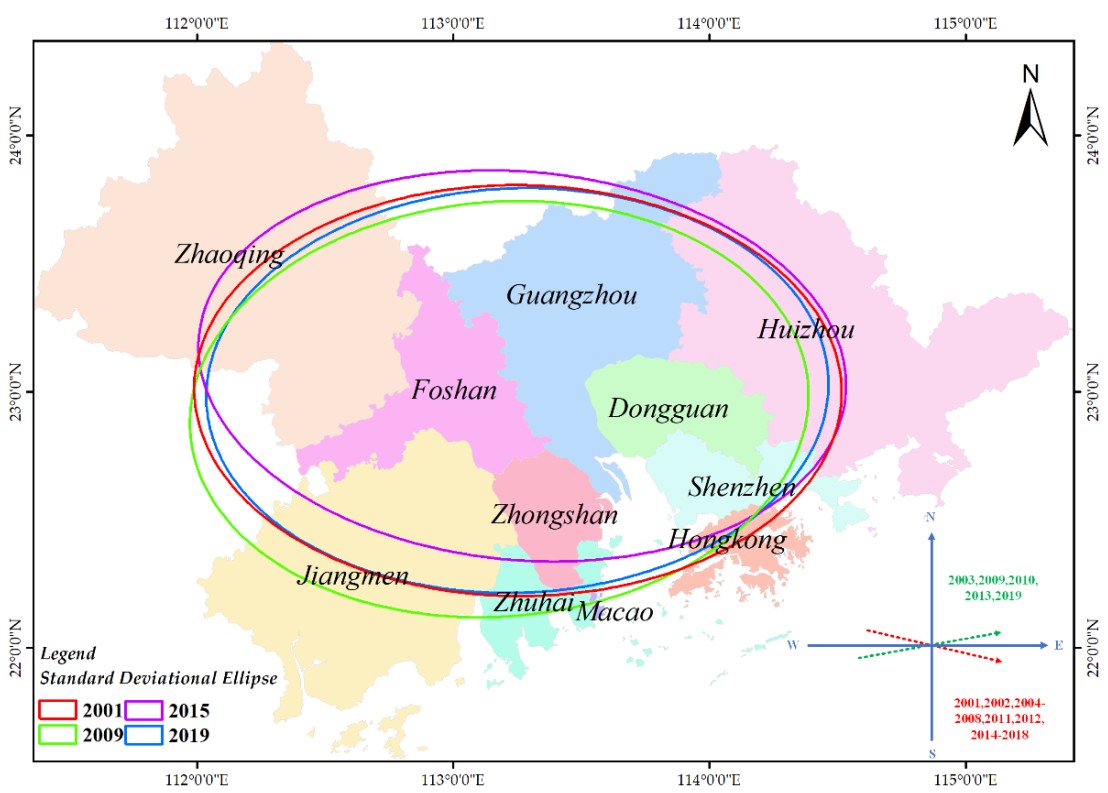

Figure 10. Spatial variation trend of precipitation in GBA from 2001 to 2019.

\subsubsection{Variation Trend of Precipitation in Different Seasons}

According to the monthly precipitation data of the GBA from 2001 to 2019, the precipitation of the four seasons of spring, summer, autumn and winter was obtained (Figure 11). In this paper, spring refers to March, April and May, summer refers to June, July, August, autumn refers to September, October and November, and winter refers to December, January, and February. The results showed that in the past 18 years, the precipitation in the GBA was mainly concentrated in spring and summer, and the precipitation in spring tended to increase gradually, while the precipitation in summer tended to decrease gradually, while the precipitation in autumn and winter had no obvious change.

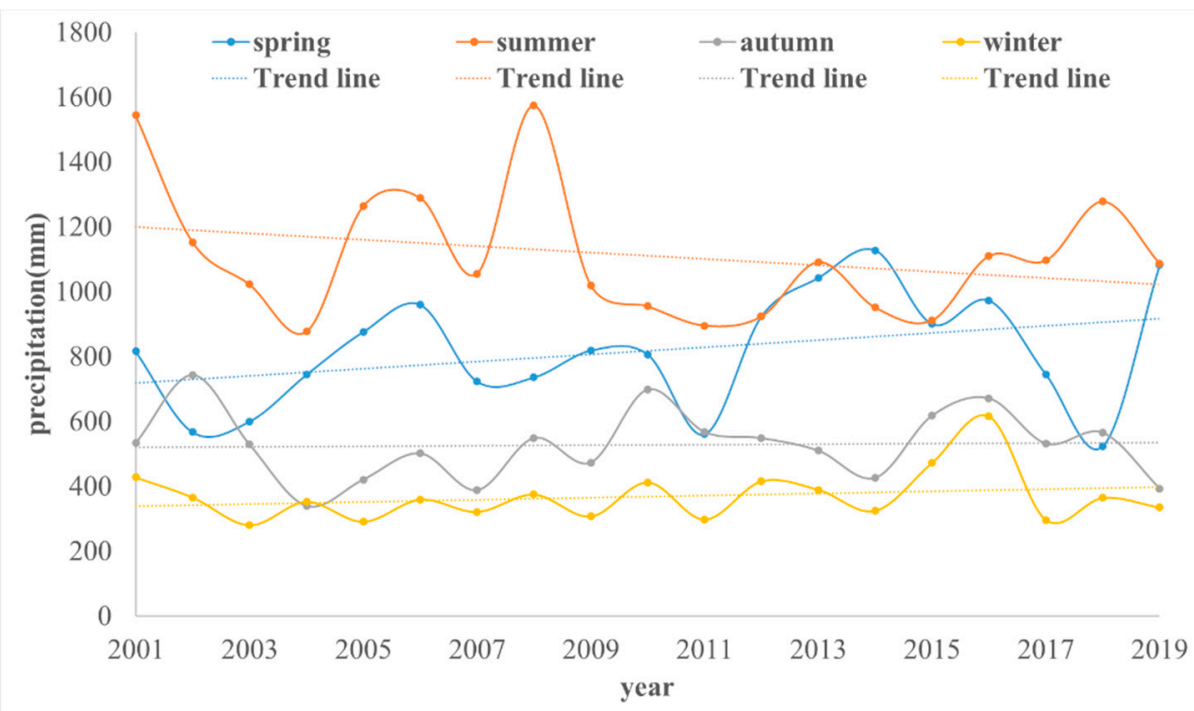

Figure 11. Total precipitation in the four quarters from 2001 to 2019. 


\subsection{The Relationship between Land Cover Land Use Change and Precipitation Change}

The annual cumulative precipitation decreased dramatically during 2001-2004, by about 50 percent, reaching its lowest point in 2004 (Figure 7). During this period, the area of forest/grassland, water and barren decreased sharply, the area of construction land increased rapidly, and the area of cropland basically remained unchanged (Figure 3). The maximum extreme precipitation occurred in 2002 and 2003, and the minimum extreme precipitation occurred in 2004 (Figure 7). In terms of space, the cumulative precipitation reduction during 2001-2004 was mainly concentrated in Jiangmen, Foshan, Zhongshan, Zhuhai, Macao Special Administrative Region, Guangzhou, Dongguan, Shenzhen, Hong Kong Special Administrative Region and Huizhou, and the annual cumulative precipitation reduction exceeded $1000 \mathrm{~mm}$. The annual cumulative precipitation in Zhaoqing decreased by about $500 \mathrm{~mm}$, which was relatively small (Figure 12a). During this period, the land cover land use change on the space was mainly concentrated in the reduced precipitation area of the pearl river delta plain, and the land cover land use structure changed mainly forest/grassland and water, barren into construction land, as construction land area increased by $635.73 \mathrm{~km}^{2}$, then reduced by $229.47 \mathrm{~km}^{2}$, water area and forest/grassland area reduced $209.08 \mathrm{~km}^{2}$, and barren area by $203.06 \mathrm{~km}^{2}$.

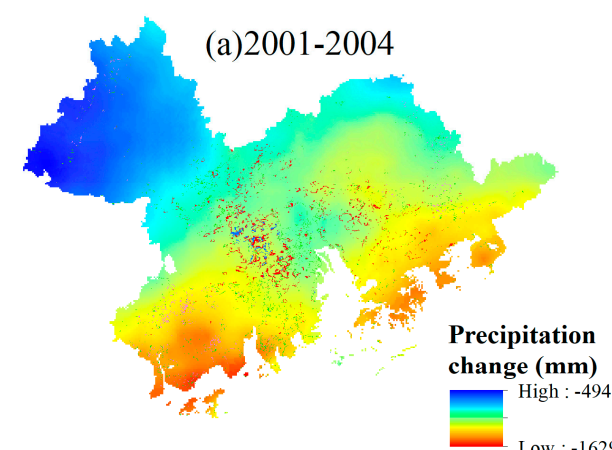

(c)2008-2011

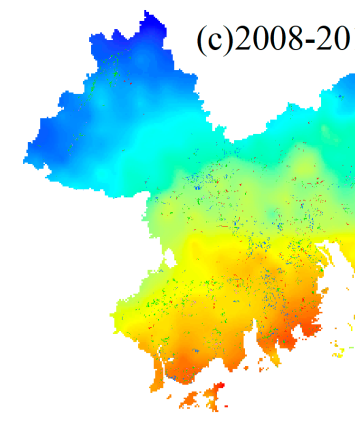

(e)2016-2019

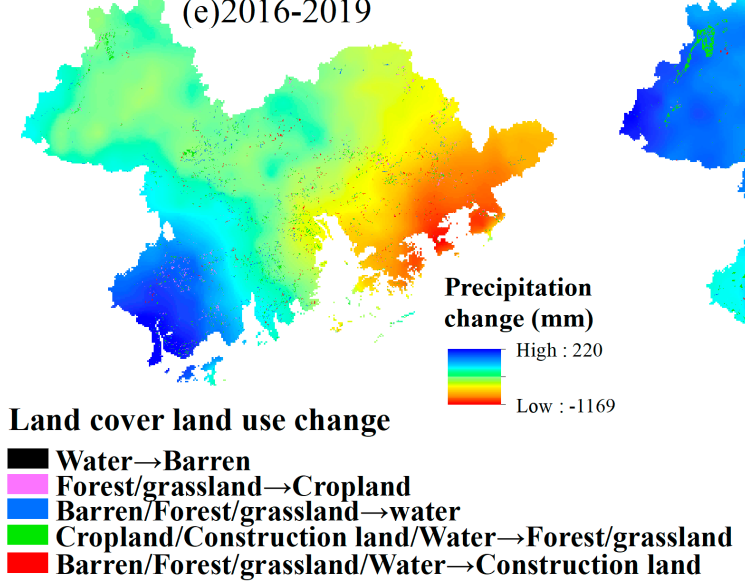
change $(\mathbf{m m})$

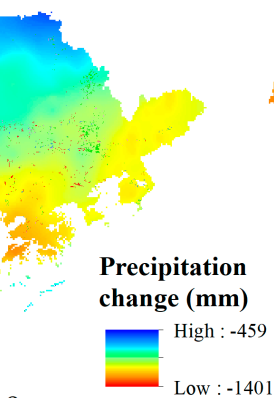

(b)2004-2008

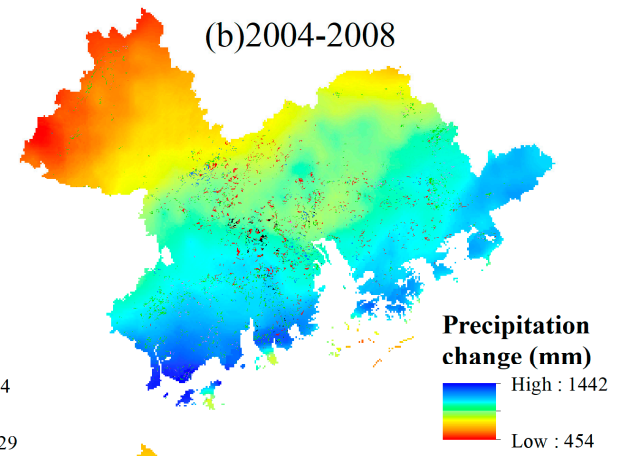

(d)2011-2016

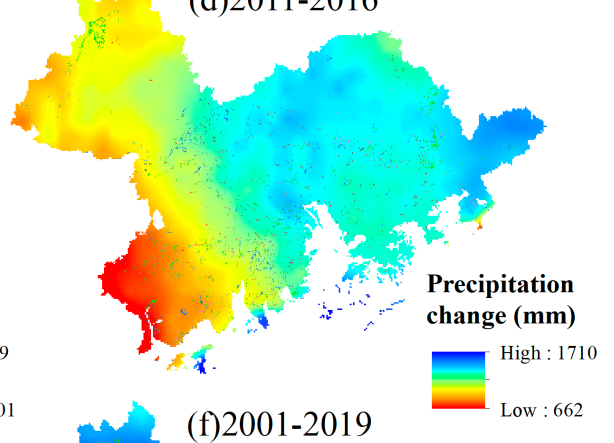

(f) 2001-2019

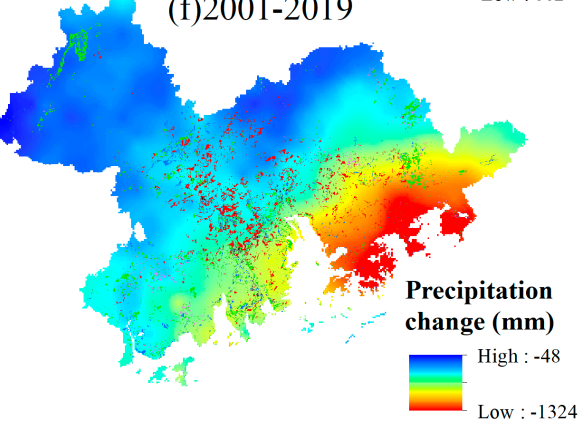

$\bigwedge^{N}$

Figure 12. Spatial superposition map of land cover land use change and precipitation change. 
The annual cumulative precipitation decreased dramatically during 2001-2004, by about 50 percent, reaching its lowest point in 2004 (Figure 7). During this period, the area of forest/grassland, water and barren decreased sharply, the area of construction land increased rapidly, and the area of cropland basically remained unchanged (Figure 3 ). The maximum extreme precipitation occurred in 2002 and 2003, and the minimum extreme precipitation occurred in 2004 (Figure 7). In terms of space, the cumulative precipitation reduction during 2001-2004 was mainly concentrated in Jiangmen, Foshan, Zhongshan, Zhuhai, Macao Special Administrative Region, Guangzhou, Dongguan, Shenzhen, Hong Kong Special Administrative Region and Huizhou, and the annual cumulative precipitation reduction exceeded $1000 \mathrm{~mm}$. The annual cumulative precipitation in Zhaoqing decreased by about $500 \mathrm{~mm}$, which was relatively small (Figure 12a). During this period, the land cover land use change on the space mainly concentrated in the reduced precipitation area of the pearl river delta plain, and the land cover land use structure changed mainly forest/grassland and water, barren into construction land, construction land area increased by $635.73 \mathrm{~km}^{2}$, then decreased by $229.47 \mathrm{~km}^{2}$, water area and forest/grassland area reduced $209.08 \mathrm{~km}^{2}$, and barren area by $203.06 \mathrm{~km}^{2}$.

From 2004 to 2008 (Figure 12b), the annual cumulative precipitation showed an increased trend, and the spatial increase was mainly in Jiangmen City, Zhongshan City, Zhuhai City, Macao Special Administrative Region, Shenzhen City, Hong Kong Special Administrative Region and Huizhou city, with the annual cumulative precipitation increasing between 1000 and $1442 \mathrm{~mm}$. The annual cumulative precipitation increased in Zhaoqing city, Guangzhou City and Foshan city was between 454 and $1000 \mathrm{~mm}$. During this period, the area of water and cropland continued to decrease, while the area of construction land continued to increase. The land cover land use structure transformation was mainly concentrated in the central region of the GBA, included Guangzhou, Foshan, Dongguan, and other places.

From 2008 to 2011 (Figure 12c), the annual cumulative precipitation showed a decreasing trend. In 2009 and 2011, extreme precipitation occurred, and the spatial reduction areas were mainly concentrated in Jiangmen city, Zhuhai City, Zhongshan City, Dongguan City, Shenzhen City, Huizhou City, Macao Special Administrative Region and Hong Kong Special Administrative Region. The annual cumulative precipitation decreased was between 800 and $1401 \mathrm{~mm}$. The annual cumulative precipitation in Zhaoqing city and the northern part of Guangzhou decreased by 459 to $800 \mathrm{~mm}$. During this period, the cropland area decreased significantly, by $248.67 \mathrm{~km}^{2}$, and the land cover land use change was mainly distributed in the areas with a large decreased in precipitation. The research showed that a significant decrease in cropland area will reduce precipitation.

From 2011 to 2016 (Figure 12d), the annual cumulative precipitation showed an increasing trend, and the spatial increased was mainly in Huizhou, Dongguan, Shenzhen, Hong Kong Special Administrative Region and Guangzhou, with the annual cumulative precipitation increasing between 1400 and $1710 \mathrm{~mm}$. During this period, the water area continued the growth trend of the previous stage, with the area increasing by $106.69 \mathrm{~km}^{2}$ and the construction land area increasing at a slower rate.

There were differences in the spatial variation of annual cumulative precipitation from 2016 to 2019 (Figure 12e). Except for the increased of precipitation in the west of Jiangmen city, precipitation in other regions has decreased to different degrees. The change of land cover land use in the west of Jiangmen city was mainly the conversion of forest/grassland to cropland, while the water area in other areas was further reduced. The conversion of forest/grassland to cropland has an increased effect on regional precipitation.

\section{Discussion}

Studies have shown that LCLUC not only affected the energy exchange between land and atmosphere, but also affected the carbon and water cycle, changed the precipitation spatial pattern, and had a significant impact on urban waterlogging and flood frequency $[42,43]$. In this study, it was found that with the change of land cover land use, 
the spatial distribution of precipitation also changed. Especially in the areas where the change of construction land was concentrated, the spatial distribution of precipitation changed most obviously.

The GBA unique topography (Figure 1), with the east, west, north three sides surrounded by mountains, south facing the sea, over the years precipitation has generally been sufficient. In recent years, the spatial and temporal distribution of GBA precipitation has undergone some changes, and extreme rainfall has become more frequent [44]. According to the spatial and temporal distribution of precipitation from 2001 to 2019, it can be found that the spatial distribution of precipitation has changed (Figure 8). Before the high level of urbanization, precipitation was mainly concentrated in the southern coastal area of the study area. In this stage, the spatial distribution of precipitation was mainly affected by topography. With the development of urbanization, land cover land use changed dramatically in space, and the spatial distribution of precipitation began to change, mainly in highly urbanized areas.

Studies have shown that LCLUC has a certain impact on climate and regional precipitation, and many scholars have carried out related studies in this regard [1-3,10,12]. Some scholars have analyzed the influence of cropland, forest, and urban change on precipitation in specific regions $[13,14,17,19,20]$. However, there have been no reports on the spatialtemporal effects of LCLUC on precipitation in the GBA, especially construction land and cropland change on regional precipitation. What characteristics exist in this region need to be studied. The change of land cover land use in the GBA was mainly the decreasing of cropland and the increasing of construction land (Figure 3). At present, existing studies have found that the change of construction land has different effects on precipitation in different regions.

According to the analysis results in this study, in the GBA, in the early stage of urbanization, the impervious area of the city is small, the LCLUC is little, and the spatial distribution of precipitation was greatly affected by the topography. After high urbanization, the concentration of atmospheric aerosol over cities increased, which was more likely to lead to the occurrence of short-term heavy precipitation due to the overall sufficient precipitation in this region. This was consistent with the research conclusions of other scholars [45]. However, the results of this study showed that there was a certain statistical correlation between LCLUC and the temporal and spatial changes of precipitation. However, the precipitation is a complex process, and several factors affect the spatial and temporal changes. Therefore further studies are needed to understand changing trends.

\section{Conclusions}

From 2001 to 2019, both land cover land use and precipitation in the GBA have undergone drastic changes. Compared with 2001, in 2019, cropland area decreased by $44.03 \%$, water area decreased by $8.05 \%$, barren area decreased by $50.22 \%$, forest/grassland area decreased by $0.43 \%$, and construction land area increased by $20.05 \%$.

The precipitation in the GBA was mainly concentrated in the spring and summer, and the precipitation in spring tended to increase gradually, while the precipitation in summer tended to decrease gradually, while the precipitation in autumn and winter had no obvious change.

The spatial distribution of precipitation changes with the continuous enhancement of human activities, with topographic factors and LCLUC as the main influencing factors.

Author Contributions: Conceptualization, P.C.; Data curation, X.W.; Funding acquisition, P.C.; Investigation, Y.J., X.J. and J.W.; Methodology, P.C.; Resources, Y.H., P.C. and Y.J.; Supervision, Y.H. and P.C.; Writing—original draft, X.W.; Writing—review and editing, Y.J. All authors have read and agreed to the published version of the manuscript.

Funding: This research was funded by the "Research on the Influence of changes of underlying Surface of fusion Radar and optical remote sensing on Precipitation - A case study of Guangzhou (No. 007073897022)" and "Research on regional net irrigation water quantity calculation Method based on remote sensing evapotranspiration model (No. 902229136010)". This project was also funded by The 
Science and Technology Program of Guangzhou, grant number 201605030009, 201803020036, and National Natural Science Foundation of Guangdong Province, China (No. 2018B030306026), Project supported by Guangdong Engineering and Research Center for Unmanned Aerial Vehicle Remote Sensing of Agricultural Water and Soil Information, and Research on Key Technologies of Poultry Supply Chain Traceability Based on Blockchain Technology (No. 2019KZDZX1001).

Institutional Review Board Statement: Not applicable.

Informed Consent Statement: Not applicable.

Data Availability Statement: Data from this research will be available upon request to the authors.

Acknowledgments: We thank the editor and reviewers for their comments on this paper.

Conflicts of Interest: The authors declare no conflict of interest.

\section{References}

1. Alireza, D.; Roy, B.; Ali, N.; Mostafa, P.; Ardavan, Z.; Fatemeh, F.M. Modelling the impacts of climate and land use change on water security in a semi-arid forested watershed using InVEST. J. Hydrol. 2021, 593, 125621.

2. Eugenia, K.; Ming, C. Impact of urbanization and land-use change on climate. Nature 2003, 423, 528-531.

3. Mahmood, R.; Sr, R.A.P.; Hubbard, K.G.; Niyogi, D.; Bonan, G.; Lawrence, P.; McNider, R.; McAlpine, C.; Etter, A.; Gameda, S.; et al. Impacts of Land Use/Land Cover Change on Climate and Future Research Priorities. Bull. Am. Meteorol. Soc. 2010, 91, 37-46. [CrossRef]

4. Meshesha, T.W.; Tripathi, S.K.; Khare, D. Analyses of land use and land cover change dynamics using GIS and remote sensing during 1984 and 2015 in the Beressa Watershed Northern Central Highland of Ethiopia. Modeling Earth Syst. Environ. 2016, 2, 1-12. [CrossRef]

5. Worku, T.; Khare, D.; Tripathi, S.K. Modeling runoff-sediment response to land use/land cover changes using integrated GIS and SWAT model in the Beressa watershed. Environ. Earth Sci. 2017, 76, 1-14. [CrossRef]

6. Worku, T.; Tripathi, S.K.; Khare, D. Household level tree planting and its implication for environmental conservation in the Beressa Watershed of Ethiopia. Environ. Syst. Res. 2018, 6, 1-10. [CrossRef]

7. Meshesha, T.W.; Tripathi, S.K. Farmer's perception on soil erosion and land degradation problems and management practices in the Beressa Watershed of Ethiopia. J. Water Resour. Ocean Sci. 2016, 5, 64-72. [CrossRef]

8. Hamere, Y.; Teshome, S.; Mekuria, A.; Ashraf, D. Changes in landscape composition and configuration in the Beressa watershed, Blue Nile basin of Ethiopian Highlands: Historical and future exploration. Heliyon 2020, 6, e04859.

9. Oskar, E.; Pål, B.; Göran, B.; Nicolae, S.; Jean, F.D.; Bruna, G.; Ioannis, D.; Blas, M.Y.; Fernando, F. Beneficial land use change: Strategic expansion of new biomass plantations can reduce environmental impacts from EU agriculture. Glob. Environ. Chang. 2020, 60, 101990.

10. Costanza, R.; De, G.R.; Sutton, P.; Vander, P.S.; Anderson, S.J.; Kubiszewski, I.; Farber, S.; Turner, R.K. Changes in the global value of ecosystem services. Glob. Environ. Chang. 2014, 26, 152-158. [CrossRef]

11. Hernández, M.M.; Plieninger, T.; Bieling, C. An empirical review of cultural ecosystem service indicators. Ecol. Indic. 2013, 29, 434-444. [CrossRef]

12. Li, B.; Huang, F.; Qin, L.; Qi, H.; Sun, N. Spatio-Temporal Variations of Carbon Use Efficiency in Natural Terrestrial Ecosystems and the Relationship with Climatic Factors in the Songnen Plain, China. Remote Sens. 2019, 11, 2513. [CrossRef]

13. Junkermann, W.; Hacker, J.; Lyons, T.; Nair, U. Land use change suppresses precipitation. Atmos. Chem. Phys. 2009, 9, 6531-6539. [CrossRef]

14. Bounoua, L.; DeFries, R.; Collatz, G.J.; Sellers, P.; Khan, H. Effects of land cover conversion on surface climate. Clim. Chang. 2002, 52, 29-64. [CrossRef]

15. Pitman, A.J.; de Noblet-Ducoudré, N.; Avila, F.B.; Alexander, L.V.; Boisier, J.P.; Brovkin, V.; Delire, C.; Cruz, F.; Donat, M.G.; Gayler, V. Effects of land cover change on temperature. Earth Syst. Dyn. 2012, 3, 213-231. [CrossRef]

16. Yan, M.; Liu, J.; Wang, Z.; Ning, L. Biogeophysical impacts of land use/land cover change on 20th century anthropogenic climate compared to the impacts of greenhouse gas change. Int. J. Clim. 2020, 40, 6560-6573. [CrossRef]

17. Jin, Y.; Zhang, H.; Yan, Y.; Cong, P. A Semi-Parametric Geographically Weighted Regression Approach to Exploring Driving Factors of Fractional Vegetation Cover: A Case Study of Guangdong. Sustainability 2020, 12, 7512. [CrossRef]

18. Li, Z.; Xu, Y.; Sun, Y.; Wu, M.; Zhao, B. Urbanization-driven changes in land-climate dynamics: A case study of Haihe River Basin, China. Remote Sens. 2020, 12, 2701. [CrossRef]

19. Jin, Y.; Liu, X.; Yao, J.; Zhang, X.; Zhang, H. Mapping the annual dynamics of cultivated land in typical area of the Middle-lower Yangtze plain using long time-series of Landsat images based on Google Earth Engine. Int. J. Remote Sens. 2020, 41, 1625-1644. [CrossRef]

20. Jin, Y.; Liu, X.; Chen, Y.; Liang, X. Land-cover mapping using Random Forest classification and incorporating NDVI time-series and texture: A case study of central Shandong. Int. J. Remote Sens. 2018, 39, 8703-8723. [CrossRef] 
21. Zhou, Q.; Zhao, X.; Wu, D.; Tang, R.; Du, X.; Wang, H.; Zhao, J.; Xu, P.; Peng, Y. Impact of urbanization and climate on vegetation coverage in the Beijing-Tianjin-Hebei Region of China. Remote Sens. 2019, 11, 2452. [CrossRef]

22. Tariq, A.; Shu, H. CA-Markov Chain Analysis of Seasonal Land Surface Temperature and Land Use Landcover Change Using Optical Multi-Temporal Satellite Data of Faisalabad, Pakistan. Remote Sens. 2020, 12, 3402. [CrossRef]

23. Zhang, C.L.; Chen, F.; Miao, S.G.; Li, Q.C.; Xia, X.A.; Xuan, C.Y. Impacts of urban expansion and future green planting on summer precipitation in the Beijing metropolitan area. J. Geophys. Res. Atmos. 2009, 114. [CrossRef]

24. Feng, J.M.; Wang, Y.L.; Ma, Z.G.; Liu, Y.H. Simulating the regional impacts of urbanization and anthropogenic heat release on climate across China. J. Clim. 2012, 25, 7187-7203. [CrossRef]

25. Freitag, B.M.; Nair, U.S.; Niyogi, D. Urban modification of convection and rainfall in complex terrain. Geophys. Res. Lett. 2018, 45, 2507-2515. [CrossRef]

26. Liu, Y.; Stanturf, J.; Lu, H. Modeling the Potential of the Northern China Forest Shelterbelt in Improving Hydroclimate Conditions 1. J. Am. Water Resour. Assoc. 2008, 44, 1176-1192. [CrossRef]

27. Gálos, B.; Hagemann, S.; Hänsler, A.; Kindermann, G.; Rechid, D.; Sieck, K.; Teichmann, C.; Jacob, D. Case study for the assessment of the biogeophysical effects of a potential afforestation in Europe. Carbon Balance Manag. 2013, 8, 1-12. [CrossRef]

28. Perugini, L.; Caporaso, L.; Marconi, S.; Cescatti, A.; Quesada, B.; de Noblet-Ducoudre, N.; House, J.I.; Arneth, A. Biophysical effects on temperature and precipitation due to land cover change. Environ. Res. Lett. 2017, 12. [CrossRef]

29. Ma, D.; Liu, Z.; Lü, S.; Michael, N.; Rong, X.; Cheng, G.; Wang, F. Short-term climatic impacts of afforestation in the East Asian monsoon region. Chin. Sci. Bull. 2013, 58, 2073-2081. [CrossRef]

30. Hagos, S.; Leung, L.R.; Xue, Y.; Boone, A.; de Sales, F.; Neupane, N.; Huang, M.; Yoon, J.H. Assessment of uncertainties in the response of the African monsoon precipitation to land use change simulated by a regional model. Clim. Dyn. 2014, 43, 2765-2775. [CrossRef]

31. Zhou, L.; Jiang, Z.; Li, Z.X.; Yang, X.Q. Numerical simulation of urbanization climate effects in regions of east China. Chin. J. Atmos. Sci. 2015, 39, 596-610.

32. Woldemichael, A.T.; Hossain, F.; Pielke Sr, R.; Beltrán-Przekurat, A. Understanding the impact of dam-triggered land use/land cover change on the modification of extreme precipitation. Water Resour. Res. 2012, 48. [CrossRef]

33. Wang, X.; Yan, F.; Su, F. Impacts of Urbanization on the Ecosystem Services in the Guangdong-Hong Kong-Macao Greater Bay Area, China. Remote Sens. 2020, 12, 3269. [CrossRef]

34. Qiao, W.; Sheng, Y.; Fang, B. Land use change information mining in highly urbanized area based on transfer matrix: A case study of Suzhou, Jiangsu Province. Geogr. Res. 2013, 32, 1497-1507.

35. Allard, J.F.; Atalla, N. Extensions to the Transfer Matrix Method; John Wiley Sons Ltd.: Hoboken, NJ, USA, 2009. [CrossRef]

36. Rahman, M.; Yang, R.; Di, L. Clustering Indian Ocean Tropical Cyclone Tracks by the Standard Deviational Ellipse. Climate 2018, 6, 39. [CrossRef]

37. Gong, J. Clarifying the Standard Deviational Ellipse. Geogr. Anal. 2002, 34, 155-167. [CrossRef]

38. Zhu, L.; Yang, A.M.; Xia, X.X.; Wu, H.Q. Spatial distribution pattern and change characteristics analysis of cultivated land in the Manas River Basin from 1975 to 2015. Chin. J. Eco-Agric. 2020, 28, 117-129.

39. Wang, B.J. Theories and methods for soil grain orientation distribution in SEM by standard deviational ellipse. Chin. J. Geotech. Eng. 2009, 07, 103-108.

40. Zhou, T.; Niu, A.Y.; Ma, J.J.; Xu, S.J. Spatio-temporal pattern of national wetland parks. J. Nat. Resour. 2019, 034, 26-39.

41. Gai, M.; Zhu, J.M.; Sun, C.Z.; Xu, K. Spatio-temporal evolution and influencing factors of Marine economic efficiency in China's coastal areas. Resour. Sci. 2018, 40, 68-81.

42. Zope, P.E.; Eldho, T.I.; Jothiprakash, V. Impacts of land use-land cover change and urbanization on flooding: A case study of Oshiwara River Basin in Mumbai, India. Catena 2016, 145, 142-154. [CrossRef]

43. Tarigan, S.D. Land cover change and its impact on flooding frequency of Batanghari Watershed, Jambi Province, Indonesia. Procedia Environ. Sci. 2016, 33, 386-392. [CrossRef]

44. Chen, W.L.; Xia, J. Analysis of causes and countermeasures of extraordinary rainstorm in 22nd, May, Guangzhou. Chin. J. Water Resour. 2020, 13, 4-7.

45. Zhang, H.; Wu, C.; Chen, W.; Huang, G.R. Effect of urban expansion on summer rainfall in the pearl river delta, south china. J. Hydrol. 2019, 568, 747-757. [CrossRef] 